\title{
Drug usage analysis in pregnant women
}

\author{
Raganova A, Petrova M, Gazova A, Kriska M, Kristova V \\ Institute of Pharmacology and Clinical Pharmacology, Faculty of Medicine, Comenius University, \\ Bratislava, Slovakia.viera.kristova@fmed.uniba.sk
}

\begin{abstract}
BACKGROUND: Drug usage in pregnant women is associated with a problem of possible negative influence on prenatal development. It is always necessary to judge the need for drug administration during pregnancy. OBJECTIVE: The aim of presented study was to analyse data about pregnant women hospitalized in the postpartum period.

METHODS: The study was designed as a retrospective observational study including 300 women hospitalized at the 2nd Department of Gynaecology and Obstetrics, University Hospital, Bratislava. Data were obtained through questionnaires in form of an interview.

RESULTS: The average age of women was $30.79 \pm 4.40$ years. Risk pregnancy occured in $20.59 \%$ of women. Chronic disorders before pregnancy required regular pharmacotherapy in $29.24 \%$. Drug usage analysis: I. trimester, $31 \%$ used at least one drug, $52 \%$ nutritional supplements, $63.3 \%$ drug and/or nutritional supplement; II. trimester, $23 \%$ used at least one drug, $45 \%$ nutritional supplements, $58.3 \%$ drug and/or nutritional supplement; III. trimester, $32 \%$ used at least one drug, $67 \%$ nutritional supplements, $75.3 \%$ drug and/or nutritional supplement.

CONCLUSION: Drug usage during pregnancy requires great precaution at choosing pharmacotherapy. The benefit of pharmacotherapy should always outweight the potential risk of administered drug (Tab. 3, Fig. 3, Ref. 37). Text in PDF www.elis.sk.

KEY WORDS: pregnancy, drug risk, prenatal development, analysis of pharmacotherapy.
\end{abstract}

\section{Introduction}

Drug administration during pregnancy represents a very specific and sensitive problem. On one side, there are fears from untreated disorder; on the other side, worry exists from possible risk of drug negative influence on healthy development of embryo and fetus (1). It is necessary to judge the need for drug administration, however rejection of pharmacotherapy during pregnancy is not always desirable. Untreated or inadequately treated maternal illness may cause teratogenic effects and worsen health of the woman (e.g. diabetes mellitus, epilepsy) or disrupt the adequate prenatal development (2).

Decision on safe drug usage during pregnancy is needed. Pregnant women are generally excluded from clinical trials due to ethical concerns about the possible effect of the drug on the embryo-fetal development (3). In particular, safety data are regularly obtained from findings of preclinical studies in animal models, published case studies, or national registries that were designed to evaluate the effect of the medicines in pregnancy (4). There exists

Institute of Pharmacology and Clinical Pharmacology, Faculty of Medicine, Comenius University, Bratislava, Slovakia

Address for correspondence: $\mathrm{V}$. Kristova, $\mathrm{MD}, \mathrm{PhD}$, Institute of Pharmacology and Clinical Pharmacology, Faculty of Medicine, Comenius University, Spitalska 24, SK-813 72 Bratislava, Slovakia. Phone: +421 290119232

Acknowedgement: This work was supported by grant VEGA 1/0112/17. only limited data on the extent of risk not only in Slovakia but also in neighboring countries. The current situation offers only little information available on the drug effects during pregnancy (5). Risk overestimation can cause inadequate treatment, while underestimation is unwanted (6). Only a limited number of medicines are labeled as safe for use during pregnancy. The decision about drug prescription may be difficult and is based on information from FDA and EMEA databases on risk assessment of medicinal products in pregnancy $(7,8)$. In most of the summaries of product characteristics, standard information about the inadequacy of the drug administration during pregnancy can be found, but in fact, only a few drugs have a proven negative effect on embryo and fetus (9). When administering medicaments, the physiological changes that occur during pregnancy and significantly affect the pharmacokinetics should be taken into consideration, as well as gestation period during which the drug exposure occured (10). The most vulnerable period for the development of birth defects is organogenesis during the first trimester. In the second and third trimester non-structural malformations such as growth retardation, central nervous system and immune system disorders can occur. Development of the central nervous system continues throughout the pregnancy and into infancy, leading to possible behavioral changes (11).

\section{Methods}

The study was designed as a retrospective observational study that included three hundred randomly selected women hospitalized 


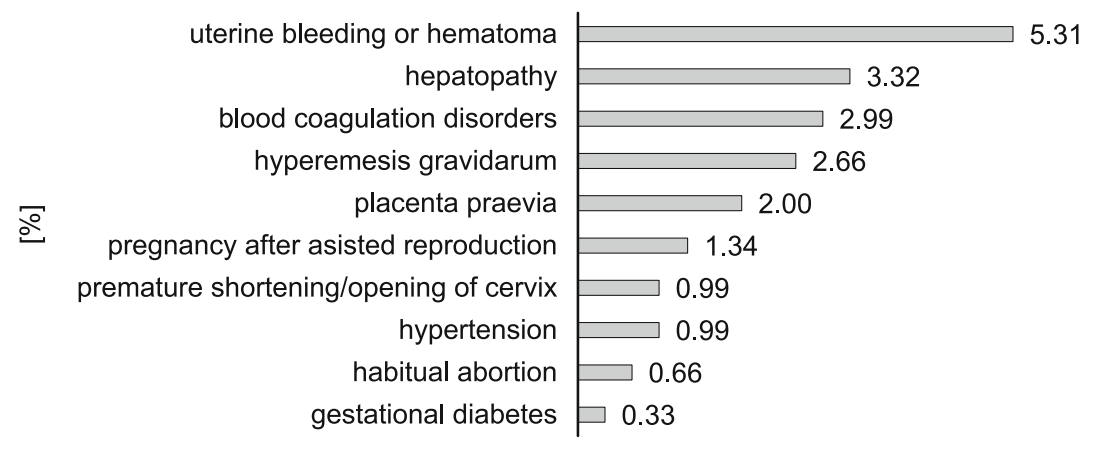

Fig. 1. Disorders complicating pregnancy (percentage of respondents, $\mathbf{n}=\mathbf{3 0 0}$ ). pregnancy. Smoking before pregnancy was reported in $11 \%$ of women: up to 40 cigarettes daily $(0.33 \%)$, up to 20 cigarettes daily $(2.31 \%)$, up to 10 cigarettes daily $(3.85 \%)$, up to 5 cigarettes daily $(2.97 \%)$, up to 2 cigarettes daily $(1.54 \%)$. Almost all women stopped smoking after pregnancy and only 0.66 $\%$ of them continued with smoking during pregnancy, but maximally 5 cigarettes daily (Tab. 2). About half of the women consumed coffee during pregnancy: one third of them one cup of coffee daily, the others two cups of coffee daily.

High-risk pregnancy occured in $20.59 \%$ of women, most commonly due to hyperemesis gravidarum, uterine bleeding or hematoma, placenta praevia, blood coagulation disorders, pregnancy after assisted reproduction, premature shortening and opening of the cervix, habitual abortion, hepatopathy, hypertension and gestational diabetes (Fig. 1). Approximately one third of mothers $(29.24 \%)$ required regular pharmacotherapy due to following chronic diseases before pregnancy: allergies, varicose veins, hypothyroidism, bronchial asthma, anemia, migraine, depression, diabetes mellitus (Fig. 2).

\section{Analysis of pharmacotherapy during pregnancy}

Women were asked about pharmacotherapy in each trimester of pregnancy. In the I. trimester of pregnancy $31 \%$ of women used at least one drug, $52 \%$ used nutritional supplements (vitamins, folic acid, magnesium, iron) and $63.3 \%$ used drug and/ or nutritional supplement (Fig. 3). The most frequently applied pharmacological groups during this period were analgesics, hormonal preparations, anticoagulants, antimicrobials, antiemetics and antihistamines. Among nutritional supplements dominated vitamins and folic acid (Tab. 3). In the II. trimester at least one drug used $23 \%$ of women, $45 \%$ used nutritional supplements and $58.3 \%$ used drug and/or nutritional supplement (Fig. 3). During the II. trimester the most commonly used drugs were analgesics, hormonal preparations, anticoagulants, antimicrobials, antihistamines, and antihypertensives. The main nutritional supplements were iron and vitamins (Tab. 3). During the III. trimester $32 \%$ of women used at least one drug, $67 \%$ used nutritional supplements

Tab. 1. Age of pregnant women (percentage of respondents, $\mathbf{n}=\mathbf{3 0 0}$ ).

\begin{tabular}{lccccc}
\hline Age (years) & $17-25$ & $26-30$ & $31-35$ & $36-40$ & $41-45$ \\
\hline$\%$ & 12.3 & 34.4 & 40 & 11.6 & 1.7 \\
\hline
\end{tabular}

Tab. 2. Comparison of smoking before and during pregnancy (percentage of respondents, $n=300$ ).

\begin{tabular}{lccccc}
\hline Cigarettes per day before pregnancy & $\leq 2$ & $\leq 5$ & $\leq 10$ & $\leq 20$ & $\leq 40$ \\
\hline \% of smoking women & 14 & 27 & 35 & 21 & 3 \\
\% of all women & 1.54 & 2.97 & 3.85 & 2.31 & 0.33 \\
\hline Cigarettes per day during pregnancy & $\leq 2$ & $\leq 5$ & $\leq 10$ & $\leq 20$ & $\leq 40$ \\
\hline \% of smoking women & 3 & 3 & - & - & - \\
\% of all women & 0.33 & 0.33 & - & - & - \\
\hline
\end{tabular}

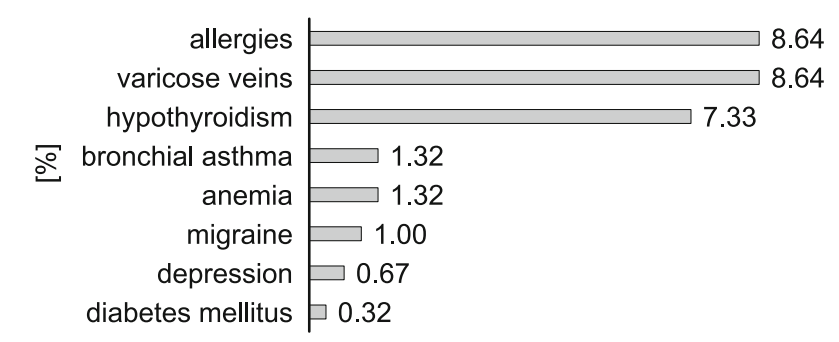

Fig. 2. Chronic diseases before pregnancy (percentage of respondents, $\mathbf{n}=\mathbf{3 0 0}$ ). 


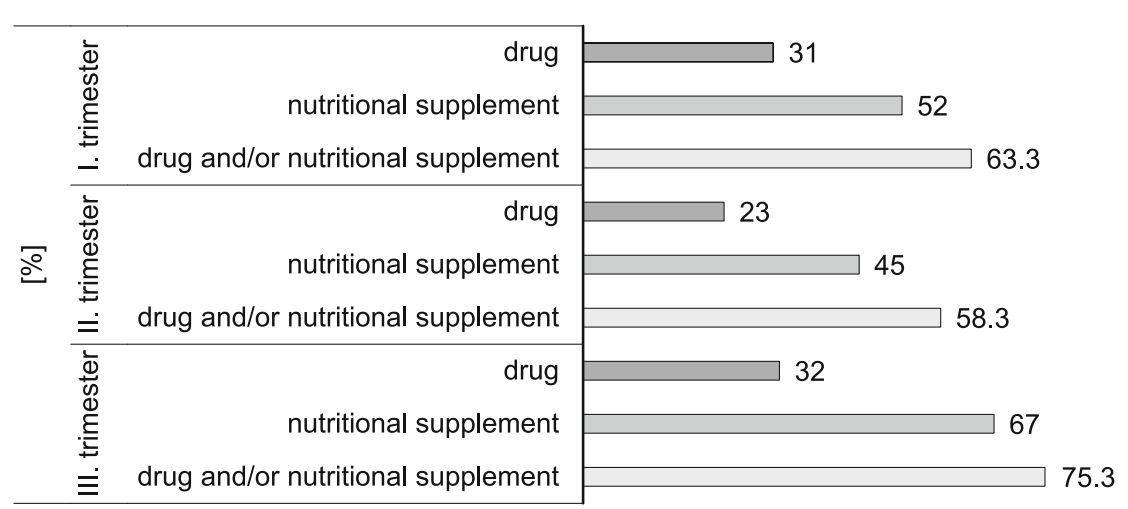

Fig. 3. Comparison of drug and nutritional supplement use in each trimester (percentage of respondents, $\mathrm{n}=300$ ).

and $75.3 \%$ used drug and/or nutritional supplement (Fig. 3). In the last trimester of pregnancy predominantly used medicaments were analgesics, anticoagulants, hormonal preparations, antimicrobials, antihistamines, antihypertensives and drugs for liver diseases. The main nutritional supplements were iron supplements (Tab. 3). During the whole pregnancy at least one drug used $45.7 \%$ of women, $37.7 \%$ of all respondents used both, drug as well as nutritional supplement and only $10.6 \%$ of women did not use any drug and/or nutritional supplement. The most commonly used drug during the whole pregnancy was paracetamol (22.7\%) and iron as nutritional supplement $(52.3 \%)$.

\section{Discussion}

The study was conducted as an interview with established questions. This method is generally used in pharmacoepidemiology and pharmacovigilance (12).

In Slovakia, as in the most of European countries, a trend of postponing parenthood to higher age is seen in recent years (13). This is in agreement with data obtained from present study. The majority of women were between $31-35$ years old. It is relatively high age, taking into consideration that around half of them were primiparae. Higher age of pregnant women is associated

Tab. 3. Use of specific drugs and nutritional supplements in each trimester (percentage of respondents, $n=300$ )

\begin{tabular}{lccc}
\hline Drugs & $\begin{array}{c}\text { I. trimester } \\
{[\%]}\end{array}$ & $\begin{array}{c}\text { II. trimester } \\
{[\%]}\end{array}$ & $\begin{array}{c}\text { III. trimester } \\
{[\%]}\end{array}$ \\
\hline Hormones & 20.7 & 11.7 & 8.7 \\
Analgesics & 13.7 & 11.2 & 8.7 \\
Anticoagulants & 8.7 & 10.1 & 10.1 \\
Antimicrobials & 3.7 & 5.1 & 7.3 \\
Antihistamines & 1.7 & 3.1 & 3.1 \\
Antihypertensives & - & 1.4 & 2.7 \\
Drugs for liver diseases & - & - & 3.3 \\
\hline Nutritional supplements & & & \\
\hline Vitamins & 26.3 & 17 & 15 \\
Folic acid & 20.3 & 8 & 8.3 \\
Iron & 7.3 & 19.3 & 47.7 \\
Magnesium & 3 & 11 & 23 \\
\hline
\end{tabular}

with increased incidence of risk pregnancies, assisted reproduction, occurence of chronic diseases with necessity of regular pharmacotherapy (14). In the present study about one fifth of respondents had risk pregnancy and almost one third of respondents suffered from chronic disease with necessity of regular pharmacotherapy. Women with chronic diseases requiring medication should have a preconception consultation that would allow a thorough discussion of the impact of their disease on pregnancy, as well as the risks and benefits of continuing a medication during pregnancy (15). There are differences between chronically ill women and healthy women in peri- and prenatal variables as well as birth outcomes on the population level. However, they are less frequent than expected (16).

It is a favorable signal that only $11 \%$ of women reported smoking before pregnancy, and after conception their number decreased radically to $0.66 \%$. On the other hand, it is alarming that there are mothers who continue despite pregnancy. Smoking during pregnancy is in relationship with premature birth and lower birth weight of the newborn. Premature labor leads to severe complications such as respiratory insufficiency and insufficient maturation of the gastrointestinal system, as well as delayed development of the nervous system. Low birth weight may increase mortality and morbidity in the neonatal age (17). Regarding consumption of caffeine, almost half of all women in this study reported consumption of coffee during pregnancy, what is a relatively high amount. A meta-analysis of seven studies in 1998 has demonstrated a significant increase in low birth weight linked with caffeine intake during pregnancy (18).

Nutritional supplements may have a protective effect on embryo-fetal development. Commonly, physicians recommend usage of prenatal vitamins and minerals. In this study prenatal vitamins were used mostly by women in the I. trimester, in the II. and III. trimesters the number slightly decreased. Although, in the presence of sufficient diet, such supplementation may lead to an upper limit for reference doses (19). Many micronutrients in excessive doses are related to health risks (20). Animal studies suggest that intrauterine exposure to high levels of vitamins and minerals increases susceptibility to obesity and metabolic abnormalities in the offspring (21).

In the I. trimester, the most frequently used supplement was folic acid, which is important for adequate fetal development during the prenatal period. Its clear importance in pregnancy lies in the process of developing the brain and the nervous system, especially in the prevention of neural tube defects (22). In Slovakia, 5 per 10,000 live-born children are affected by congenital malformations of the central nervous system. Some drugs, in particular folic acid antagonists (anticonvulsants, trimethoprim and others), significantly increase the risk of neural tube defects in children of women during the critical period of development (23). 
867-871

Iron was used mainly in the III. trimester. Iron deficiency is the leading cause of anemia in pregnancy with an estimated worldwide prevalence of $20-80 \%$. In addition to the general consequences of anemia, there are specific risks to the mother and fetus during pregnancy, such as intrauterine growth retardation and preterm birth (24). Much attention is given to conditions of iron deficiency and iron deficient anemia, because of the high global prevalence estimated in this vulnerable life stage. Preliminary evidence demonstrates a U-shaped risk at both low and high iron status for birth and infant adverse health outcomes including growth, preterm birth, gestational diabetes, gastrointestinal problems, and neurodegenerative diseases during aging (25).

At least one drug (not including nutritional supplements) was used by $45.7 \%$ of women during pregnancy (26). Compared to other developed countries, this number is similar. In a retrospective study including more than 19000 women, about $90 \%$ were taking at least one medication (either prescription drug or overthe-counter drug) during the pregnancy (27).

In the present study, hormonal preparations were the most frequently administered drugs. In the first trimester $20.7 \%$ of women used dydrogesterone and levothyroxine. Dydrogesterone reduces the risk of miscarriage and is mostly used at the beginning of pregnancy (28). Thyroid hormones are neccessary for healthy fetal development (29). Decreased thyroid activity before pregnancy and regular pharmacotherapy with levothyroxine reported $7.32 \%$ of respondents. Levothyroxine has no evidence for drug-induced teratogenicity or foetotoxicity in humans at recommended doses (29). The second most frequently used medicaments in present study were analgesics, predominantly paracetamol (acetaminophen). In study performed by Werler et al (2005) paracetamol, as an over-the-counter medication, was used at least $65 \%$ of the time (30). Paracetamol is the safest antipyretic and analgesic medicine for nocioceptive pain in pregnancy, while it should be used shortterm and at the lowest effective dose (31).

Since from varicose veins suffered $8.64 \%$ of women before conception, to often prescribed drugs belonged fraxiparine as anticoagulant. Low-molecular weight heparins are preferentially administered in pregnancy, since they do not cross the placental barrier (32). Many times infectious diseases cannot be avoided in pregnancy (33). Anti-microbial agents prescribed in this study were predominantly beta-lactam antibiotics (penicillins and cephalosporins), which have long-term good experience with regard to possible teratogenicity (34). Allergic diseases before conception were reported by $8.64 \%$ of women surveyed. Both asthma and atopic conditions may worsen, improve or remain the same during pregnancy. Intranasal and inhaled steroids are relatively safe to continue during pregnancy (e.g. budesonide), preferred are the second-generation antihistamines as cetirizine and loratadine (35).

The results of present study suggest that in Slovakia there is sufficient education in the area of drug risk in pregnancy. A certain number of mothers even completely eliminate the medication during pregnancy because of the fear of disturbed fetal development. Results of a multinational European study conducted in 15 European countries show that the most women used medications classified as safe, only about one-third used medications classified as risky, and 3\% used medications with no classification available (36). The benefit of pharmacotherapy applied in pregnancy must always outweigh the risks it carries, but only few recently approved pharmaceuticals by FDA contain human data in their pregnancy section (37). On the other hand, the disease itself can be teratogenic. Therefore, to absolutely avoid the use of drugs in pregnancy is not desirable.

\section{Conclusion}

In pharmacotherapy during pregnancy, the drug is applied to the mother, while embryo and fetus become an undesirable recipients and its effect is manifested as unwanted. It is necessary to minimize the risk on prenatal development and in treatment of acute or chronic diseases of pregnant women are preferred drugs that have long-term experience over the newer ones. Obtained results through surveys represent a suitable way how to collect information on drug usage in pregnancy that can be helpful in formation of national databases.

\section{References}

1. Benevent J, Montastruc F, Damase-Michel C. The importance of pharmacoepidemiology in pregnancy-implications for safety. Expert Opin Drug Saf 2017; 16(10): 1181-1190.

2. Lai T, Xiang L, Liu $Z$ et al. Association of maternal disease and medication use with the risk of congenital heart defects in offspring: a case-control study using logistic regression with a random-effects model. J Perinat Med 2019; 47 (4): 455-463.

3. Alsmadi MM, Idkaidek N. Optimization of Drugs. Pharmacotherapy During Pregnancy Using Physiologically Based Pharmacokinetic Models - An Update. N. Curr Drug Metab 2018; 19 (12): 972-978.

4. Knoppert D. Safety and efficacy of drugs in pregnancy. J Popul Ther Clin Pharmacol 2011; 18 (3): e506-512.

5. Smolina K, Hanley GE, Mintzes B, Oerlander TF, Morgan S. Trends and Determinants of Prescription Drug Use during Pregnancy and Postpartum in British Columbia, 2002-2011: A Population-Based Cohort Study. PLoS One 2015; 10 (5): e0128312.

6. Gils C, Pottegard A, Ennis ZN, Damkier P. Perception of drug teratogenicity amonng general practitioners and specialists in obstetrics/gynecology: a regional and national questionnaire-based survey. BMC Pregnancy Childbirth 2016; 16: 226.

7. Pernia S, DeMaagd G. The New Pregnancy and Lactation Labeling Rule Pharmacy and Therapeutics 2016 ; 41 (11): 713-715.

8. EMEA guideline on the exposure to medicinal products during pregnancy: Need for post-authorisation data. EMEA/CHMP/313666/2005.

9. Arguello B, Salgado TM, Fernandez-Llimos F. Assessing the information in the Summaries of Product Characteristics for the use of medicines in pregnancy and lactation. Br J Clin Pharmacol 2015; 79 (3): $537-544$.

10. Tasnif Y, Morado J, Hebert MF. Pregnancy-related pharmacokinetic changes. Clin Pharmacol Ther 2016; 100 (1): 53-62.

11. Wawruch et al. Kapitoly z klinickej farmakológie, UK Bratislava, 2012, 176 . 
12. Karakitsiou M, Varga Z , Kriska M, Kristova V. Risk perception of NSAIDs in hospitalized patients in Greece. Bratislavske Lekarske Listy 2017; 118 (7):427-430.

13. Mosakova EA. The demographic transition in Spain in the 20th and 21st centuries: Transforming the family and marriage institution. Iberoamerica 2019; 1: 149-169.

14. Waldenstrom U. Postponing parenthood to advanced age. Upsala J of Med Sciences 2016; 121 (4): 235-243.

15. Riley LE, Cahill AG, Beigi R, Savich R, Saade G. Improving Safe and Effective Use of Drugs in Pregnancy and Lactation: Workshop Summary. Am J Perinatol 2017; 34: 826-832.

16. Kersten I, Lange AE, Haas JP et al. Chronic diseases in pregnant women: prevalence and birth outcomes based on the SNiP-study. BMC Pregnancy and Childbirth 2014; 14: 75.

17. Andriani H, Kuo HW. Adverse effects of parental smoking during pregnancy in urban and rural areas. BMC Pregnancy Childbirth 2014; 14: 414

18. Rhee J, Kim, R, Kim Y, Tam M, Lai Y, Keum N, Oldenburg CE. Maternal Caffeine Consumption durig Pregnancy and Risk of Low Birth Weight: A Dose-Response Meta-Analysis of Observational Studies. PLoS One, 2015; 10 (7): e 0132334.

19. Sanchez-Hernandez D, Anderson GH, Poon AN, Pannia E, Cho CE, Huot PSP, Kubnat R. Maternal fat-solubile vitamins, brain development, and regulation of feeding behavior: an overview of research. Nutr Res 2016; 36 (10): 1045-1054.

20. Gernard AD. The upper level: examining the risk of excess micronutrient intake in pregnancy from antenatal supplements. Ann N Y Acad Sci 2019; 1444 (1): 22-34.

21. Szeto IM, Das PJ, Aziz A, Anderson GH. Multivitamin supplementation of Wistar rats during pregnancy accelerates the development of obesity in offspring fed an obesogenic diet. Int J Obes 2009; 33: 364-372.

22. Revakova T, Revak O, Vasilenkova A, Behulova D, Brucknerova I. Amount of folic acid in different types of nutrition used in the neonatal period. Bratisl Lek Listy 2015; 116 (6): 349-353.

23. Horn F, Sabova L, Pinterova E, Hornova J, Trnka J. Prevention of neural tube defects by folic acid - awareness among women of childbearing age in Slovakia. Bratisl Lek Listy 2014; 115 (2): 91-97.

24. Breymann C. Iron Deficincy Anemia in Pregnancy. Semin Hematol 2015; 52 (4): 339-347.
25. Brannon PM, Taylor CL. Iron Supplementation during Pregnancy and Infancy: Uncertainties and Implications for Research and Policy. Nutrients 2017; 9 (12): E1327.

26. Bonati M, Tognoni G. Collaborative Group On Drug Use In Pregnancy (CGDUP). An international survey on drug utilization during pregnancy. Int J Risk Saf Med. 1991; 2 (6): 345-9.

27. Mitchell AA, Gilboa SM, Werler MM, Kelley KE, Louik C, Hernandez-Diaz S. National Birth Defects Prevention Study. Medication use during pregnancy, with particular focus on prescription drugs: 1976-2008. Am J Obstet Gynecol 2011; 205 (1): 511-518.

28. Kumar A, Begum N, Prasad S, Aggarwal S, Sharma S. Oral dydrogesterone treatment during early pregnancy to prevent recurrent pregnancy loss and ins role in modulation of cytokine production: a double-blind, randomized, parallel, pacebo-controlled trial. Fertility and sterility. 2014; 102 (5): 1357-1363.

29. Li J, Shen J, Qin L. Effects of Levothyroxine on Pregnancy Outcomes in Women With Thyroid Dysfunction: A Meta-analysis of Randomized Controlled Trials. Altern Ther Health Med 2017; 23 (2): 49-58.

30. Werler MM, Mitchell AA, Hernandez-Diaz S, Honein MA. Use of over-the-counter medications during pregnancy. Am J Obstet Gynecol 2005; 193 (3): 771-777.

31. Toda K. Is acetaminophen safe in pregnancy? Scand J Pain 2017; 17: $445-446$.

32. Simeone R, Giacomello R, Bruno G, Parco S, Maximova N, et al. Thrombogenesis in Thrombophilic Pregnancy: Evaluation of Low-Molecular-Weight Heparin Prophylaxis. Acta Haematol 2017; 137 (4): 201-206.

33. Kupermann AA, Koren O. Antibiotic use during pregnancy: how bad is it? BMC Med 2016; 14 (1): 91.

34. Muanda FT, Sheehy O, Bérard A. Use of antibiotics during pregnancy and the risk of major congenital malformations: a population based cohort study. Br J Clin Pharmacol 2017; 83 (11): 2557-2571.

35. Gonzalez-Estrada A, Geraci SA. Allergy Medications During Pregnancy. Am J Med Sci 2016; 352 (3): 326-331.

36. Tronnes JN, Lupattelli A, Nordeng H. Safety profile of medication used during pregnancy: results of a multinational European study. Pharmacoepidemiology and drug safety $2017 ; 26: 802-811$.

37. Moore KL, Persaud TVN, Torchia MG. The Developing Human: Clinically Oriented Embryology. Philadelpia, PA: Elsevier; 2015.

Received June 26, 2019. Accepted August 22, 2019. 